\title{
Development of a Strategic Model for Freight Transportation with a Case Study of the Far East
}

\author{
Louis Coulet ${ }^{1}$, Sungbum Jun ${ }^{2}$, and Jinwoo Park ${ }^{2, *}$ \\ ${ }^{1}$ Thales Services, Sophia-Antipolis, France \\ 1dc200@gmail.com \\ ${ }^{2}$ Dept. of Industrial Engineering at Seoul National University, Seoul, Republic of Korea \\ junsb87@mailab.snu.ac.kr, autofactesnu.ac.kr
}

\begin{abstract}
Developing a strategic model has become a major concern for decision-makers owing to free trade agreements (FTAs), environmental pollution and the risk of changing route conditions. The main purpose of this study is to evaluate the effect of these factors by measuring the performance of a complete transportation solution in terms of cost, delivery time and environmental impact. To solve the problem within reasonable time, the proposed model was linearized and solved by using the software ILOG OPL. This study also compared the optimal solutions under four different configurations. The proposed model may be useful for both exporting companies and government agencies as a tool for evaluating the benefits of new alternative routes.
\end{abstract}

Keywords: Freight transportation, Strategic Transportation model, Linear optimization, Korea-Europe trade.

\section{Introduction}

Freight transportation has become a major international concern owing to free trade agreements (FTAs), potential environmental pollution, and changing route conditions. FTAs are ratified to remove all tariff and non-tariff barriers on imports and exports. With the advent of FTAs, yearly commercial traffic across borders has increased considerably. Modern societies have experienced an increase in public awareness of the environmental impact that human polluting activities may have on the environment. The risk of attacks by Somali pirates and the frozen Artic Ocean also have a strong influence on transportation route selection.

Thus, anticipating environmental changes and evaluating different solutions is crucial to successfully adapting to the changes. This paper describes a strategic model for freight transportation that was developed to assist decision-makers like government planners, regulators, and shipping managers. The proposed model considers the effects of changes in the situation and route optimization to fulfill the demand of each

\footnotetext{
* Corresponding author.
} 
market. Four experiments are presented; an aggregated objective function (AOF) was used to obtain more realistic solutions.

\section{$2 \quad$ Literature Review}

Transportation models have been studied thoroughly since the advent of computers, which enabled researchers and companies to develop detailed models (Vidal, 1995).

Albino et al. (2002) proposed a model that analyzes the flows and performances of a supply chain comprising transformation processes. To consider the environmental impact of a multistep chemical supply chain, Bojarski et al. (2009) proposed a holistic model. They applied their model to a maleic anhydride production supply chain spanning Western Europe. These two analytical models are relevant to a supply chain as a series of decisions (load balancing, paths, processes, distribution centers and suppliers locations, etc.), each with different performances and capacities, that lead to a particular supply chain network.

Lainez (2009) proposed an interesting transportation model that includes the dimen-sion of flexibility and presented the detailed performance of a complex supply chain consisting of several processes. He introduced capacity limitation in supply chain channels.

Onuoha (2009) researched piracy around the Gulf of Aden. He provided figures and tried to explain the causes of the recent rise in piracy. Gilpin (2009) proposed a busi-ness model to estimate the overall cost of piracy and proposed some solutions to lessen its cost. His model has proven useful in estimating the cost suffered by shipping companies - mainly insurance fees — but the solutions cannot be evaluated.

The following sections introduce a strategic transportation model that integrates rele-vant parts of previous approaches to select routes that minimize the cost, time, and environmental effects. This paper presents the design of an optimal supply chain in terms of several performance criteria (i.e., net present value, environmental impact, and delivery time) under different conditions.

\section{Transportation Model}

The proposed transportation model considers three performance criteria: delivery time, cost, and environmental impact. These criteria are expressed for each of the three parts of the transportation network. The first part is one of the four approach routes from Korea to Europe: through the Suez Canal, around the Cape of Good Hope, through the Arctic Ocean, and through Siberia via the Trans-Siberian-Railroad (TSR). The second part links the four approach points to the seaports. The third part links the seaports to the markets over the entire EU27.

The equations linking the performance criteria to the quantity transported along a certain path can be simplified into a linear model with an aggregated objective function (AOF). 


\subsection{Model Definition}

Variables. The decision variables of the model are as follows:

Quantity from route a to seaport s (TEU): $\left(\mathrm{y}_{\mathrm{as}}\right)_{\mathrm{a} \in \mathrm{A}, \mathrm{s} \in \mathrm{S}}$

Quantity from seaport s to market $m$ (TEU): $\left(\mathrm{z}_{\mathrm{sm}}\right)_{\mathrm{s} \in \mathrm{S}, \mathrm{m} \in \mathrm{M}}$

The quantity on route a: $\left(\mathrm{X}_{\mathrm{a}}\right)_{\mathrm{a} \in \mathrm{A}}$, is completely determined by $(\mathrm{C} 2)$.

Constraints. The demand of each market at time $t\left(\operatorname{Dem}_{\mathrm{m}}(t)\right)$ is given by the forecast of the GDP of $m$ :

$\operatorname{Dem}_{\mathrm{m}}(\mathrm{t})=$ Exports $(\mathrm{t}) * \frac{\mathrm{GDP}_{\mathrm{m}}(\mathrm{t})}{\sum_{\mathrm{m} \in \mathrm{M} G \mathrm{GP}_{\mathrm{m}}(\mathrm{t})}}$.

For a permanent state with no stocks held anywhere in the network,

The demand of each market is fulfilled (C1): $\sum_{s \in \mathrm{s}} \mathrm{z}_{\mathrm{sm}}=\operatorname{Dem}_{\mathrm{m}}(\mathrm{t}), \forall \mathrm{m} \in \mathrm{M}$

Steady state on the visiting path (C2): $\sum_{\mathrm{s} \in \mathrm{S}} \mathrm{Y}_{\mathrm{as}}=\mathrm{X}_{\mathrm{a}}, \forall \mathrm{a} \in \mathrm{A}$

Steady state on the distribution (C3): $\sum_{\mathrm{a} \in \mathrm{A}} \mathrm{y}_{\mathrm{as}}=\sum_{\mathrm{m} \in \mathrm{M}} \mathrm{z}_{\mathrm{sm}}, \forall \mathrm{s} \in \mathrm{S}$

Measures. The average delivery cost for market $m$ (USD/TEU) is

$\operatorname{Cost}_{\mathrm{m}}=\frac{1}{\operatorname{Dem}_{\mathrm{m}}} \sum_{\mathrm{s} \in \mathrm{S} / \mathrm{Y}_{\mathrm{s}}>0}\left[\mathrm{c}^{\mathrm{z}}\left(\mathrm{z}_{\mathrm{sm}}\right)+\frac{\mathrm{z}_{\mathrm{sm}}}{\mathrm{Y}_{\mathrm{s}}} \sum_{\mathrm{a} \in \mathrm{A} / \mathrm{X}_{\mathrm{a}}>0} \frac{\mathrm{y}_{\text {as }}}{\mathrm{X}_{\mathrm{a}}}\left(\mathrm{c}^{\mathrm{X}}\left(\mathrm{X}_{\mathrm{a}}\right)+\mathrm{c}^{\mathrm{Y}}\left(\mathrm{y}_{\mathrm{as}}\right)\right)\right]$,

where the total quantity in seaport $s$ is $\mathrm{Y}_{\mathrm{s}}=\mathrm{a} \in \mathrm{A} \mathrm{y}_{\mathrm{as}}$

The overall average environmental impact (ton eq. $\mathrm{CO}_{2} / \mathrm{TEU}$ ) is

$$
\text { Impact }=\frac{1}{\text { Exports }}\left(\sum_{\mathrm{a} \in \mathrm{A}} \mathrm{p}^{\mathrm{X}}\left(\mathrm{X}_{\mathrm{a}}\right)+\sum_{\mathrm{a} \in \mathrm{A}} \sum_{\mathrm{s} \in \mathrm{S}} \mathrm{p}^{\mathrm{y}}\left(\mathrm{y}_{\mathrm{as}}\right)+\sum_{\mathrm{m} \in \mathrm{M}} \sum_{\mathrm{s} \in \mathrm{S}} \mathrm{p}^{\mathrm{z}}\left(\mathrm{z}_{\mathrm{sm}}\right)\right) \text {. }
$$

The average delivery time for market $m$ is

Time $_{\mathrm{m}}=\frac{1}{\text { Dem }_{\mathrm{m}}} \sum_{\mathrm{s} \in \mathrm{S} / \mathrm{Y}_{\mathrm{s}}>0}\left[\mathrm{t}^{\mathrm{z}}\left(\mathrm{z}_{\mathrm{sm}}\right)+\frac{\mathrm{z}_{\mathrm{sm}}}{\mathrm{Y}_{\mathrm{s}}} \sum_{\mathrm{a} \in \mathrm{A} / \mathrm{X}_{\mathrm{a}}>0} \frac{\mathrm{y}_{\mathrm{as}}}{\mathrm{X}_{\mathrm{a}}}\left(\mathrm{t}^{\mathrm{X}}\left(\mathrm{X}_{\mathrm{a}}\right)+\mathrm{t}^{\mathrm{Y}}\left(\mathrm{y}_{\mathrm{as}}\right)\right)\right]$.

\subsection{Objective Function}

Route allocation is a multi-objective optimization problem since three self-competing criteria are being optimized. A mix of the different routes with the lowest cost, lightest environment impact, and quickest delivery of the goods is desired.

Aggregated Objective Function (AOF):

$$
\operatorname{AOF}\left(\begin{array}{c}
\left(y_{\text {as }}\right)_{\mathrm{a} \in \mathrm{A}, \mathrm{s} \in \mathrm{S}} \\
\left(\mathrm{z}_{\mathrm{sm}}\right)_{\mathrm{s} \in \mathrm{S}, \mathrm{m} \in \mathrm{M}} \\
(\kappa, \varphi, \theta)
\end{array}\right)=\kappa * \text { Cost }+\varphi * \text { Impact }+\theta * \text { Time }
$$


The coefficient $\varphi$ translates the environmental impact in terms of cost, so the dimension of $\varphi$ is [(USD/USDtransported)/unit of impact/USD] $=$ [USD/unit of impact]. The amount $\varphi *$ Impact can be considered a tax on the impact on the environment that has been progressively appearing in reality. The coefficient $\theta$ translates the delivery time in terms of cost, so the dimension of $\theta$ is [(USD/USDtransported)/days] = $[\mathrm{USD} /($ days $\times \mathrm{USDt})]$. Goods that are on their way to their final markets constitute idle stocks, so they generate an opportunity cost to their owner (should it be the producer or final consumer) that can be represented by $\theta *$ Time. Then, $\theta=\mathrm{E} \times$ ONIA can be used, where $\mathrm{E}$ is the amount of exports (USD) and ONIA is the overnight index average, or the cost incurred by keeping 1 USD of inventory for 1 day.

\section{$4 \quad$ Experiment and Results}

This section presents solutions to optimize transportation problems between Europe and Korea using the proposed model with four different configurations. The increase in piracy in the Gulf of Aden, length of the route to circumvent the Cape of Good Hope, melting of the Arctic Ocean, and limited capacity of the TSR as well as the distribution of demand were considered to solve the transportation model at the strategic level.

\subsection{Experimental Description}

The South Korean economy relies massively on its industrial sector, which exports high value added goods worldwide. Exports are growing rapidly as Korean companies have become serious global competitors in all industrial fields. Thus, the challenge of transportation between Korea and Europe is optimizing the time, cost, and environmental impact of long and dangerous routes between Korea and Europe. Moreover, as the planet and political concerns over it are heating up, Somali pirates have increased their attacks on more and bigger ships and the Arctic is melting, worsening the situation considerably.

In the experiment, the decision variables were the amount on each part of the route, and constraints were determined earlier. The objective function was the AOF. 37 seaports (including the TSR terminal) and 50 markets were considered for 1,850 decision variables minus 50 because of the demand constraint.

As shown above, the approach and harbor selection steps can be merged into a single set of decision variables. There are 10 seaport selection paths supplying 37 seaports, so there are 370 decision variables; however, because of the path themselves, only 153 are non-zeros. Because of the steady-state constraint, the amount unloaded in a seaport is equal to the amount sent from it to the markets, which translates into 37 constraints. Overall, the model consisted of 1,916 independent variables and a linear objective function. 
The linear model was solved using the software ILOG OPL. The solution was the absolute optimal solution and was reached in less than a second. ILOG's engine contains the code of the optimization algorithm; the user can tweak its parameters and has to define the model.

Constraint $\mathrm{C} 1$ denotes the demand of each market that has to be fully fulfilled. $\mathrm{C} 2$ represents the steady state so that the three parts of the transportation course are the same. The linear model is simple and can be expressed quickly in ILOG because the objective function is simply a linear combination of the decision variables weighted by the cost, time, and pollution performances.

The model was optimized along the AOF to include the cost, weighted function of the total delivery time, and environmental impact. This section describes the optimal solutions in three configurations. In the first configuration, all four routes were available (Arctic, TSR, Suez Canal, and the Cape of Good Hope routes). In the second configuration, the Arctic route was considered unavailable; in the third configuration, only the Suez Canal and the Cape of Good Hope routes were available. The influence of increased piracy was evaluated and represented in configuration 4.

\subsection{Results}

Configuration 1. Figure 1 shows the transportation course when all routes were available. Europe was mostly supplied through the Arctic route. However, the Suez route performed better when delivering to the Italian, Greek, Turkish, and Balkan markets. The TSR only supplied Moscow and Kastornoye.

In this configuration, the delivery time ranged from 18.4 days for Norway to 23.8 days for Seville in Spain. The cost and pollution level were at their lowest in Norway (1,255 USD and 3.42) and highest in Romania and Bulgaria (1,806 USD and 8.17) as long land transportation was required. The importance (around $36 \%$ of goods) of the Bremerhaven and Rotterdam seaports should be noted.

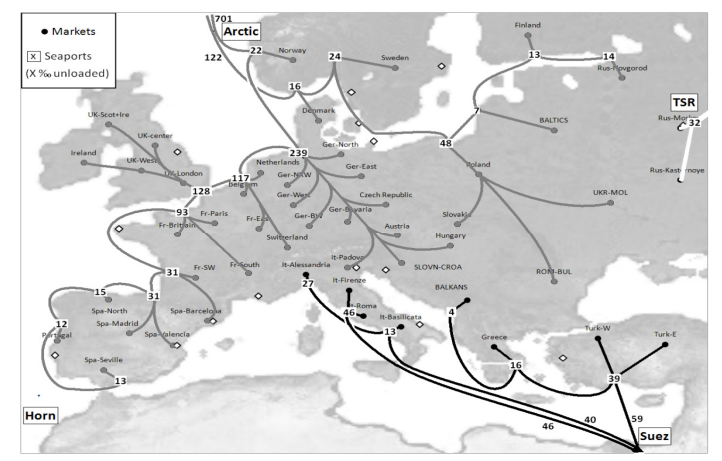

Fig. 1. Optimal transportation course of configuration 1: all routes available 


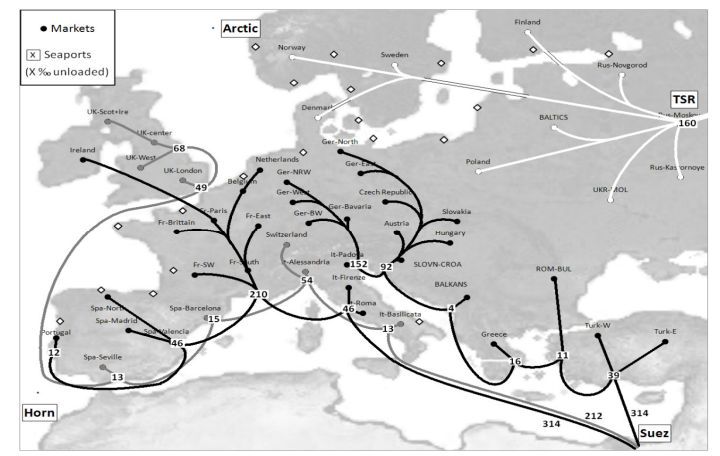

Fig. 2. Optimal transportation course of configuration 2: Artic Ocean frozen

Configuration 2. As the Arctic route, through which most of Europe was supplied in configuration 1, was no longer available, the area supplied through the Suez route expanded to most of Europe except for the northeastern area supplied through the TSR. In configuration 2 , the performances sharply declined. The delivery time ranges from 20.3 days for Moscow, which was the terminal of the TSR, to 29.3 days for northern UK. The cost ranged from 1,456 USD for Moscow to 2,308 USD for Ireland; pollution ranges from 4.01 for southern Italy to 11.51 for Norway. More than $45 \%$ of goods were unloaded in the harbors of Marseille, Venetia, and Rijeka.

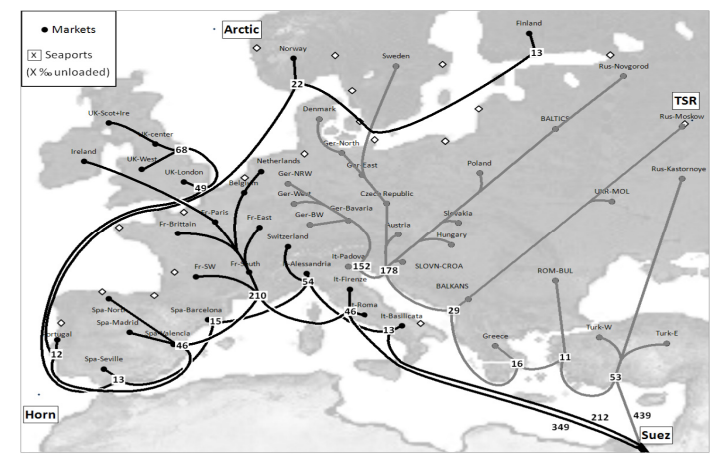

Fig. 3. Optimal transportation course of configuration 3: only Suez available

Configuration 3. The solution for configuration 3, where only the Suez Canal and the Cape of Good Hope routes were available, is presented in Fig. 3. Most of the markets were supplied through Mediterranean and Adriatic harbors, so a large volume of south-to-north land transportation was required. This considerably reduced the performances, especially the environmental impact. Of the goods, 54\% were unloaded in the harbors of Marseille, Venetia, and Rijeka and then transported as far as Ireland, Sweden, and Novgorod. 
The delivery time ranged from 21.2 days for Turkey to 31.9 days for Finland. The cost was from 1,609 USD for southern Italy to 2,391 USD for Finland, and the pollution level was from 4.01 for southern Italy to 11.49 for northern Russia.



Fig. 4. Comparison of performances in three configurations

The overall weighted average performances in the three configurations were compared. Figure 4 shows the cost, time, and pollution of the optimal solutions in the three configurations.

The first configuration with the four routes available was taken as the reference $(100 \%)$ as it was the best in terms of cost, time, and pollution. Suppressing the Arctic line led to an $18 \%$ increase in time, $25 \%$ increase in cost, and a staggering $35 \%$ hike in environmental impact. Suppression of the TSR route affected the performance to a lesser extent with increases of 3\%-5\%. The distribution part from seaport to market was rather fast compared to the route part but was costly and generated a lot of pollution.

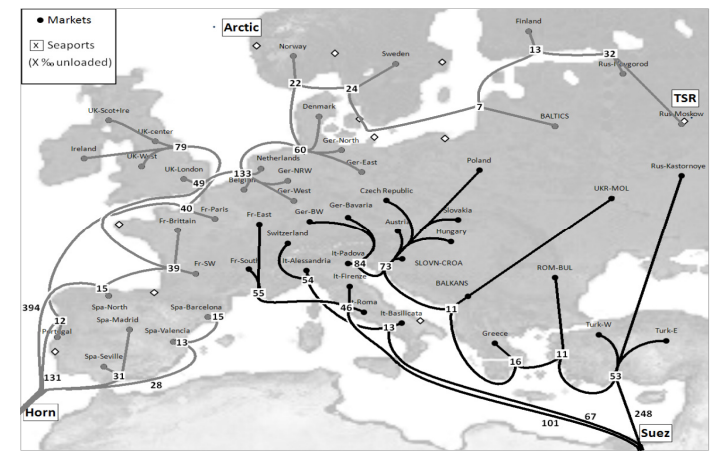

Fig. 5. Optimal transportation course of configuration 4: under increased piracy

Configuration 4. As Gilpin (2009) proposed, rerouting ships around Africa mitigates the cost of piracy. For every level of piracy and Suez Canal fee, there is a tradeoff between a longer route or a more expensive and risky one. Configuration 4 represents the transportation solution where a hypothetical increase in piracy has forced $60 \%$ of the shipments to go around the Cape of Good Hope. 
Ships going around Africa were preferred for all seaports from Barcelona around the northern coast of Europe to St. Petersburg as the relative benefit of the Suez route decreased when the distance between the Suez Canal and a seaport increased.

These results can be used to find the optimal transportation course in different situations. They can also be used to evaluate the opportunity of further developing the TSR and Arctic routes which may greatly improve the performance of the transportation network.

\section{Conclusion}

In this study, the overall transportation course at a strategic level was modeled by expressing three performance criteria (cost, time, and pollution). The performance was mainly linear with regard to the transported quantity on a particular route. The relative importance of the nonlinear performance was neglected as an approximation. The linear model was implemented and optimized with the software ILOG. Although the proposed model was based on linear assumptions, it was relatively easy to obtain good solutions within a reasonable timeframe, and the model offers a significant amount of flexibility to decision-makers who can experiment with different configurations.

The optimal solution with all four routes available showed that the Arctic and TSR are very efficient and that the Suez route proved to be best only when delivering goods to Turkey, Greece, and Italy. The developed model may be useful for both exporting companies and government agencies as a tool to evaluate the benefits of developing new alternative routes.

\section{References}

1. Albino, V., Izzo, C., Kühtz, S.: Input-output models for the analysis of a local/global supply chain. International Journal of Production Economics 78(2), 119-131 (2002)

2. Bojarski, A.D., Laínez, J.M., Espuña, A., Puigjaner, L.: Incorporating environmental impacts and regulations in a holistic supply chains modeling: An LCA approach. Computers \& Chemical Engineering 33(10), 1747-1759 (2009)

3. Raymond, G.: Counting the Costs of Somali Piracy. Center for Sustainable Economies. United States Institute of Peace, Washington DC (2009)

4. Laínez, J.M., Kopanos, G., Espuña, A., Puigjaner, L.: Flexible design-planning of supply chain networks. AIChE Journal 55(7), 1736-1753 (2009)

5. Onuoha, F.: Sea piracy and maritime security in the Horn of Africa: The Somali coast and Gulf of Aden in perspective. African Security Studies 18(3), 31-44 (2009)

6. Gilpin, R.: Counting the Costs of Somali Piracy, Center for Sustainable Economies, United States Institute of Peace Working Paper (2009)

7. Vidal, C.J., Goetschalckx, M.: Strategic production-distribution models: A critical review with emphasis on global supply chain models. European Journal of Operational Research 98(1), 1-18 (1997) 